\title{
Module partitioning study of specialized engineering services based on modular theory - case on coal production firms
}

\author{
Xin $\mathrm{WANG}^{1, *}$, Bo $\mathrm{LUO}^{2}$, Qian Yu MAO ${ }^{3}$, Hui ZHANG \\ ${ }^{1}$ School of Management Xi'an University of Science and Technology Xi'an, Shaanxi 710054, China \\ ${ }^{2}$ School of Management Xi'an Polytechnic University Xi'an, Shaanxi, 710048, China \\ ${ }^{3}$ School of Management Xi'an University of Science and Technology Xi'an, Shaanxi 710054, China \\ ${ }^{4}$ School of Management Xi' an University of Science and Technology Xi' an, Shaanxi 710054, China
}

\begin{abstract}
Outsourcing of specialized engineering services has become one of the routes to the innovation and high-quality development of the commercial model of coal production enterprises in China. Currently, although there is practice, no scale-up development has been achieved.In this paper, based on modular theory, under the condition of unknown expert weights, triangular fuzzy number method is used to construct a service unit association relationship evaluation model, and the correlation matrix is calculated. Then, a genetic algorithm is used to cluster the association matrix and obtain the results of the division of the outsourced module of engineering services. Finally, the proposed method is validated using the coal mine development process of coal producers as an example.
\end{abstract}

\section{Introduction}

In 2016, the tenth five coal industry development program encouraged coal enterprises to establish specialized service companies [1]. This program provides specialized engineering services to coal production firms and provides policy support for conducting business model innovations.

Coal specialized engineering services are available at home and abroad [2]. Cum according to the service demand party needs, improve mine design, resource distribution, business management and other engineering service activities. However, in practice, specialized engineering services for coal production fail to achieve scale effects because service content is formed based on negotiation between the supply and demand parties, and as a result, there is a lack of standardized service products.

Hongling Xu (2007) argues that modularity in service product design is the basis of industrialization [3]. Modular theory was proposed by Baldwin and Clark at Harvard Business School in 1997 [4]. Xia Hui (2010) considers service modularity as the modularity of service processes, thus forming a series of activities to meet the demands of different markets [5]. Gomes (2008) and Zhang Qianjun (2015) argue that appropriate task modularity has a positive effect on firm performance [6] [7]. Based on the above studies, this paper argues that the service modularity theory can guide the coal production specialty to provide services for industrialization and scale development.

The basis of service module design is module partitioning. References [8-14] have studied the problem of task module partitioning from different perspectives and methods. However, there is a lack of multidimensional analysis of association relationships, in terms of quantitative research, neglecting the effect of expert opinion on evaluation results, and often using fuzzy clustering, the accuracy of its calculation results is affected by artificially set thresholds and is not objective enough. Therefore, this paper proposes a service modularity design method based on multidimensional fuzzy association relationship analysis and solving the optimal module partition scheme.

\section{MODELING THE RELATIONSHIP BETWEEN SERVICE UNITS}

The smallest unit studied in this paper is the service unit. It has independently complete functions, including the operation of accomplishing active tasks. Basis of module division.

\subsection{Linguistic Scale of Association Mode and Relationship Strength}

Set up service unit collection $S=\left\{S_{1}, S_{2}, S_{3} \ldots S_{n}\right\}$, $S_{i}$ and $S_{j}$ are two elements in the $S$. According to reference [15], the relationship between $S_{i}$ and $S_{j}$ can be divided into: independent, coupled and dependent, as shown in Tab.1.

*Corresponding author: glxywx@xust.edu.cn 
Table1. ASSOCIATION MEEHOD OF SERVICE UNIT

\begin{tabular}{|c|c|c|}
\hline $\begin{array}{l}\text { Relation } \\
\text { mode }\end{array}$ & Relation intensity & Illustration \\
\hline $\begin{array}{c}\text { Parallel } \\
\text { dependency }\end{array}$ & $\begin{array}{l}\mathrm{S}_{i} \text { is the running condition of } \\
\mathrm{S}_{j}, \text { which can be subdivided into } \\
\text { parallel dependency andserial } \\
\text { dependency according to the } \\
\text { execution state of running time }\end{array}$ & \\
\hline $\begin{array}{c}\text { Serial } \\
\text { dependency }\end{array}$ & $\begin{array}{l}\mathrm{S}_{\mathrm{i}} \text { is the running condition of } \mathrm{S}_{j} \text {, } \\
\text { which can be subdivided into } \\
\text { parallel dependency andserial } \\
\text { dependency according to the } \\
\text { execution state of running time }\end{array}$ & \\
\hline Coupling & $\begin{array}{l}\mathrm{S}_{\mathrm{i}} \text { and } \mathrm{S}_{\mathrm{j}} \text { are mutually operating } \\
\text { conditions }\end{array}$ & \\
\hline Independent & $\begin{array}{l}\mathrm{S}_{i} \text { and } \mathrm{S}_{j} \text { can run without the } \\
\text { execution of the other party }\end{array}$ & \\
\hline
\end{tabular}

In this paper, six different semantic scales are established, as shown in Tab.2.

Table2. LANGUAGE VALUES AND CORRESPONDING TRIGONOMETRIC FUZZY NUMBERS

\begin{tabular}{|c|c|c|}
\hline $\begin{array}{c}\text { Relation } \\
\text { mode }\end{array}$ & Language scale of relation mode & $\begin{array}{c}\text { Triangular } \\
\text { fuzzy } \\
\text { number }\end{array}$ \\
\hline independent & $\mathrm{S}_{\mathrm{i}}$ is not associated with $\mathrm{S}_{j}$ & $(0,0,0)$ \\
\hline $\begin{array}{c}\text { Parallel } \\
\text { dependency }\end{array}$ & $\begin{array}{c}\text { Weak correlation between } \mathrm{S}_{\mathrm{i}} \text { and } \\
\mathrm{S}_{j}\end{array}$ & $(0,0.1,0.3)$ \\
\hline coupling & $\begin{array}{c}\text { The relationship between } \mathrm{S}_{\mathrm{i}} \text { and } \mathrm{S}_{j} \\
\text { is general }\end{array}$ & $(0.2,0.3,0.4)$ \\
\hline independent & $\begin{array}{c}\text { The relationship between } \mathrm{S}_{i} \text { and } \mathrm{S}_{j} \text { is } \\
\text { strong }\end{array}$ & $(0.4,0.5,0.6)$ \\
\hline
\end{tabular}

\subsection{Ruantification of Service Unit Relationship}

(1) Representation of service unit association matrix

The relationship between service units is a binary relationship, which can be expressed as:

$$
\left.R_{b}=\left\{\left(S_{i}, S_{i}\right) \mid S_{i}, S_{i}\right) \in S_{,} S_{i} R_{S_{i}}, i, j=1,2,3 \ldots n\right\}
$$

The triangular fuzzy language evaluation information given by evaluator $\mathrm{p}(p \in[1, k])$ constitutes. The evaluation matrix: $\tilde{R}_{i j}^{p}=\left(\tilde{\gamma}_{i j}^{p}\right)_{n \times n}$ :

$$
\tilde{R}_{i j}^{p}=S_{1}\left(\begin{array}{ccc}
\tilde{\gamma}_{11}^{p} & \cdots & \tilde{\gamma}_{1 n}^{p} \\
\vdots & \ddots & \vdots \\
\tilde{\gamma}_{n 1}^{p} & \cdots & \tilde{\gamma}_{n n}^{p}
\end{array}\right)
$$

$\tilde{\gamma}_{i j}^{p}$ is the evaluation value of evaluator $\mathrm{P}$ for the correlation between service units $\mathrm{S}_{i}$ and $\mathrm{S}_{j}$. It is represented by trigonometric fuzzy language $\tilde{\gamma}_{i j}^{p}=\left(\tilde{\gamma}_{i j}^{l p}, \tilde{\gamma}_{i j}^{m p}, \tilde{\gamma}_{i j}^{u p}\right), \gamma_{i j}^{l p}, \gamma_{i j}^{m p}, \gamma_{i j}^{u p}$ represents the lower limit, the most likely value and the upper limit of the value of the degree of the binary. Association of the service unit given by the evaluator. The algorithm of triangular fuzzy number is:

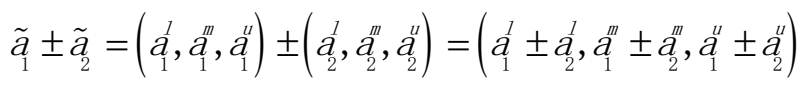

$$
\lambda \tilde{a}=\left(\lambda a^{l}, \lambda a^{m}, \lambda a^{u}\right)
$$
experts

(2) Consistency of expert opinions and weight of

Based on the evaluation information of each expert, the mean value of triangular fuzzy number of the strength of the relationship between service units is obtained

$$
\overline{\tilde{\gamma}}_{i j}=\frac{1}{k} \sum_{p=1}^{k} \tilde{\gamma}_{i j}^{p}
$$

$1-d\left(\tilde{a}_{1}, \tilde{a}_{2}\right)$ represents the similarity between two triangular fuzzy numbers. The larger the value is, the more consistent the two triangular fuzzy numbers are. The distance between two triangular fuzzy numbers can be measured by Euclidean distance:

$$
d\left(\tilde{a}_{1}, \tilde{a}_{2}\right)=\sqrt{\left[\left(a_{1}^{l}-a_{1}^{l}\right)^{2}+\left(a_{1}^{m}-a_{2}^{m}\right)^{2}+\left(a_{1}^{u}-a_{2}^{u}\right)^{2}\right] / 3}
$$

Average consistency of evaluation opinions of an expert $D_{i j}^{p}$ :

$$
D_{i j}^{p}=1-d\left(\tilde{\gamma}_{i j}^{p}, \overline{\tilde{\gamma}}_{i j}\right)
$$

The individual weight of expert $\mathrm{P}$ can be normalized by (7):

$$
\omega_{i j}^{p}=\frac{D_{i j}^{p}}{\sum_{P=1}^{K} D_{i j}^{p}}
$$

(3) Service unit Association calculation

The triangular fuzzy number of the association relationship is calculated according to the expert weight.

$$
\tilde{\gamma}_{i j}=\sum_{p=1}^{k} \tilde{\gamma}_{i j}^{p} \times \omega_{i j}^{p}
$$

The average area method was used to make the image clear.

$$
\gamma_{i j}=\frac{\gamma_{i j}^{l}+2 \gamma_{i j}^{m}+\gamma_{i j}^{u}}{4}
$$

\section{DIVISION OF SERVICE MODULES}

\subsection{Construction of Objective Function}

According to the literature [15] [16] in this paper, modularity degree is used to evaluate the module division results.

$$
Q=\sum_{i=1}^{n}\left(e_{i i}-a_{i}^{2}\right)
$$

Row (or column) $a_{i}=\sum_{j=1}^{m} e_{i j}$ Denotes the number of edges connected to the vertex [15]. Edges are between vertices, expressed as $e_{i j}=a_{i} \cdot a_{j}$. The 
optimal module partition scheme should have the maximum value of modularity [15].

Suppose there are $\mathrm{n}$ attributes. Firstly, the modularity of each attribute is calculated $Q_{\mathrm{m}}(\mathrm{m}=1, \ldots . . \mathrm{n})$, weight $\mu_{\mathrm{m}}$, and $\sum_{m=1}^{n} \mu_{m}=1$. Calculation of integrated modularity $Q_{\text {total }}$.

$$
Q_{\text {total }}=\sum_{m=1}^{n} \mu_{m} Q_{m}
$$

Targeting comprehensive modularity.

$$
F(Q)=\max \left(Q_{\text {total }}\right)
$$

\subsection{Others}

This paper uses integer coding, and gene values for each individual in the initial population are generated by uniformly distributed random numbers. Chromosomes were selected by the disk selection method using single point crossover with pc set to $[0.25,0.75]$, pm was set at $[0.01,0.2]$. The number of iterations was set to $100-5000$ times.

\section{CASE ANALYSIS}

\subsection{Identification Of Specialized Service Units Of Coal Production Enterprises}

Based on the principle of technology behavior, combined with field investigation in coal production enterprises, this paper forms a list of service units as in Tab.3.

\begin{tabular}{|c|c|c|c|}
\hline $\mathrm{NO}$ & Service unit & $\mathrm{NO}$ & Service unit \\
\hline 1 & Mine design & 2 & $\begin{array}{l}\text { Environmental protection } \\
\text { engineering }\end{array}$ \\
\hline 3 & $\begin{array}{l}\text { Administrative } \\
\text { engineering }\end{array}$ & 4 & Hoisting engineering \\
\hline 5 & $\begin{array}{l}\text { Power-supply } \\
\text { engineering }\end{array}$ & 6 & Ventilation engineering \\
\hline 7 & Auxiliary engineering & 8 & Mining \\
\hline 9 & Drivage & 10 & $\begin{array}{l}\text { Supporting and installation } \\
\text { Of equipment }\end{array}$ \\
\hline 11 & Lifting system & 12 & Ventilation and drainage \\
\hline 13 & Power supply & 14 & Moving upside down \\
\hline 15 & Coal Preparation & 16 & Provisioning \\
\hline 17 & Coal transportation & 18 & Sales \\
\hline 19 & $\begin{array}{l}\text { Equipment } \\
\text { maintenance }\end{array}$ & 20 & Equipment leasing \\
\hline 21 & $\begin{array}{l}\text { Mine } \\
\text { constructiontechnical } \\
\text { consultation }\end{array}$ & 22 & Technical consultation \\
\hline 23 & Training & & \\
\hline
\end{tabular}

Table3. LIST OF SPECIALUZED SERVICE UNITS

\subsection{Relationship Measurement of Professional Service Unit}

Based on [2] and [17-19], this paper reviews the relationship between service units in three dimensions, safety, function and economy. Space is limited, only some of the results of this review are truncated, as summarized inTable4.

Table4. SEVICE UNITS SECURITY RELATIONSHIP EVALUATIO

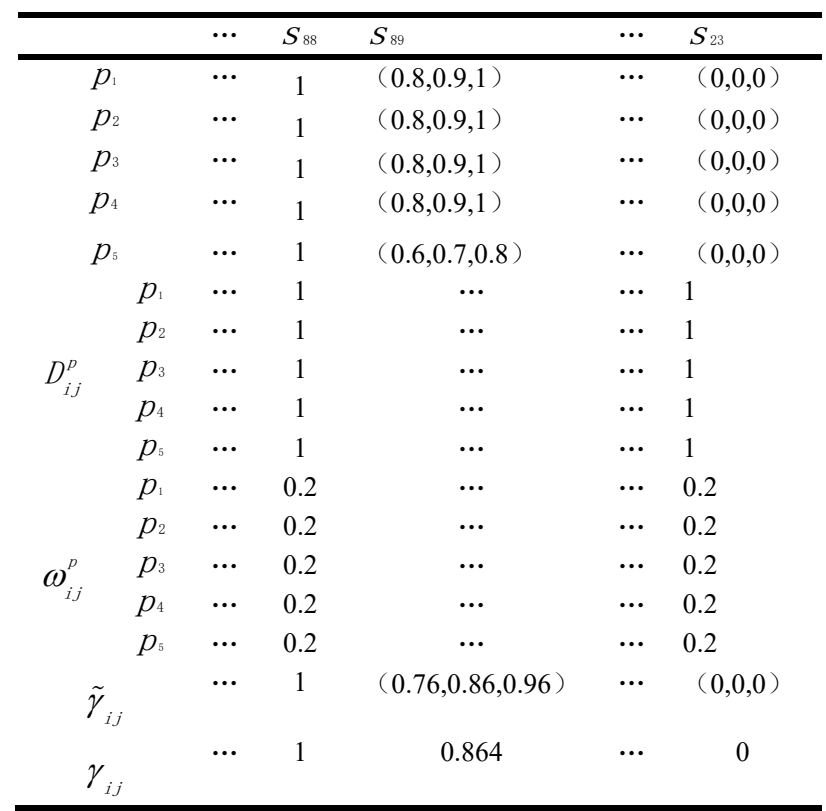

The security association matrix of service unit is obtained by calculation $R_{i j}^{s}=\left(\gamma_{i j}^{s}\right)_{23 \times 23}$

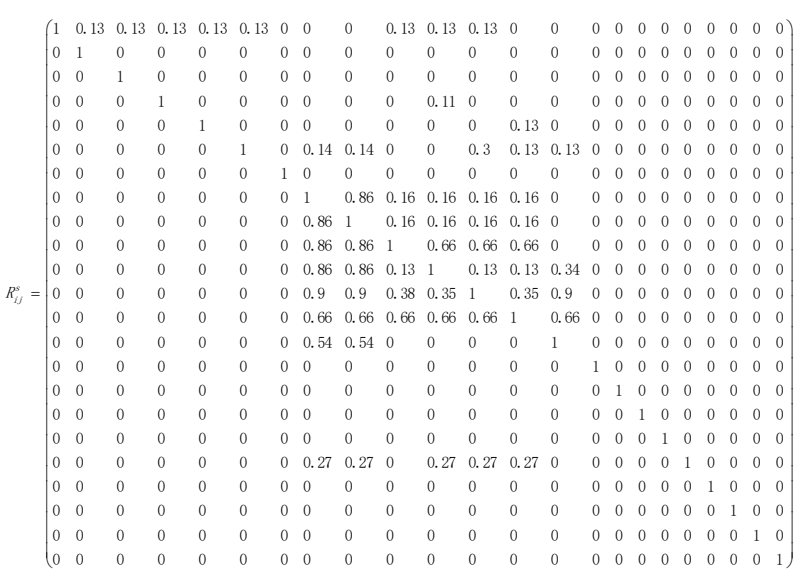

Similarly, we can calculate the economic relation matrix $R_{i j}^{e}=\left(\gamma_{i j}^{e}\right)_{23 \times 23}$ 、 function relation matrix $R_{i j}^{f}=\left(\gamma_{i j}^{f}\right)_{23 \times 23}$ (get it from 463906442@qq.com).

\subsection{Division Scheme Solution and Result Analysis of Coal Specialized Service Module}

In this paper, the parameters of the GA were set as follows: $\mathrm{n}=60, \mathrm{pc}=0.45, \mathrm{pm}=0.01$. Calculations were performed using MATLAB 2016a version. The results showed that it could be divided into 14 modules, as shown in Table 5 . 
Table5. SEVICE UNITS SECURITY RELATIONSHIP EVALUATION

\begin{tabular}{|c|c|c|c|}
\hline Modules & Service unit & Modules & Service unit \\
\hline 1 & $\begin{array}{l}\text { Technical } \\
\text { consultation }\end{array}$ & 2 & Coal Preparation \\
\hline 3 & Sales & 4 & $\begin{array}{l}\text { Environmental } \\
\text { protection engineering }\end{array}$ \\
\hline 5 & $\begin{array}{l}\text { Administrative } \\
\text { engineering }\end{array}$ & 6 & Equipment leasing \\
\hline 7 & Provisioning & 8 & $\begin{array}{l}\text { Mine construction } \\
\text { technical consultation }\end{array}$ \\
\hline 9 & $\begin{array}{l}\text { Equipment } \\
\text { maintenance }\end{array}$ & 10 & Auxiliary engineering \\
\hline 11 & Training & 12 & Coal transportation \\
\hline 13 & \multicolumn{2}{|c|}{$\begin{array}{l}\text { Mining、Drivage、Transportation and hoisting、 } \\
\text { Ventilation and drainage、Power supply、 }\end{array}$} & $\begin{array}{l}\text { Supporting and installation of equipment } \\
\text { moving upside down }\end{array}$ \\
\hline 14 & \multicolumn{3}{|c|}{$\begin{array}{l}\text { Power supply engineering、 Administrative } \\
\text { engineering }\end{array}$} \\
\hline
\end{tabular}

\section{CONCLUSION}

This paper presents the division method of engineering specialized service module and practices in combination with coal production enterprises. In cases where the expert weights were unknown, a triangular fuzzy number method was adopted to evaluate the association relationship and calculate the expert weights. And genetic algorithm is employed to calculate the optimal service module partitioning scheme. The research results of this paper provide the foundation for the development of the professional division of labour and professional service industrialization of coal enterprises.

\section{Acknowledgment}

This work was supported by National Social Science Fundation of China (No. 19BGL183); Key scientific research plan of Shaanxi Provincial Department of Education of China (key research base of philosophy and Social Sciences, No. 18JZ039); National Science and Technology Support Program of China (No. 2013BAH12F00); National Natural Science Foundation of China (No. 71273206); National Sof Science Projects of China (No. 2013GXS4D151).

\section{References}

1. N. E. A. National DevelopmentReform Commission, "The 13th Five-YearPlanfor Coal Industry Development. National Development and Reform Commission", National Energy Administration, National DevelopmentReform Commission, Bejing, China, 2016.

2. Bo Luo,Jinsuo Zhang,Zhenyu Li, "Service Risk Evaluation of the General Contract for Coal Mine Production and Operation: Case Study at Shendong Jinjie Coal Mine in China," Mathematical Problems in Engineering, Vo 2019, 2019.
3. Xu Hongling, "On the origin of the theory of business structure and the breakthrough of the dilemma of modularization," Foreign economy and management, 2007, (4): 33-60.

4. Masahiko Aoki. "Modular era - the essence of new industrial structure",Shanghai: Shanghai Far East publishing house, 2003: 64-65

5. Xia Hui, Xue Qiuzhi. "Research on modular development of service industry,. Shanghai Economic Research, 2010 (03): 28-34

6. Paulo J. Gomes, and Nitin R. Joglekar. "Linking modularity with problem solving and coordination efforts." Managerial \& Economics 29.5(2010):443-457.

7. Zhang Qianjun, Liu Yi, Wang Liang. "The impact of task modularization and process integration on the performance of offshore IT outsourcing projects", Journal of management, 2015 (04): 114-120

8. Frenken K, Mendritzki S.“Optimal modularity: a demonstration of the evolutionary advantage of modular architectures",Journal of Evolutionary Economics, 2012, 22(5):935-956.

9. Lau Antonio, K. W. , R. C. M. Yam , and E. Tang . "The impacts of product modularity on competitive capabilities and performance: An empirical study." ,International Journal of Production Economics ,105(2007).

10. Wang Wei, Liu Fuxian. "Operational task decomposition optimization based on task relation matrix", Military operations research and systems engineering, 2017 (4): 9-14

11. Feng Liangqing, Huang Dali, he Zhen.’Process modularization analysis method for complex product development project", Industrial engineering, 2018, 21 (3): 4-13

12. Tu Jianwei, Li Yan, Li Wenqiang. "Research on modular method of product family design based on FDSM", Modular machine tool and automatic machining technology, 2011 (08): 16-20

13. Chen Jian, Mo Rong, Chu Jianjiel. "Modular reconfiguration and allocation method of collaborative tasks for industrial design cloud service platform",Computer integrated manufacturing system, 2018, 24 (003): 720-730

14. Malone T W . "Tools for Inventing Organizations : Toward a Handbook of Organization Processes", Inventing the Organizations of the 21st Century, 2003.

15. M E J, Newman,M, Girvan.“,Finding and evaluating community structure in networks",.Physical review. E, Statistical, nonlinear, and soft matter physics,2004,69(2 Pt 2):026113.

16. Zhang Qing, Li Kerong. "Research on the life cycle of resource exhausted Enterprises: a case study of coal enterprises", Coal economy research, 2005 (1): 8-12

17. Zhu Liyi, LV Wensheng, Yang Peng, “2007-2016 national coal mine accident statistics and occurrence law", Coal mine safety (07). 2017 
18. J. H. Saleh and A. M. Cummings, "Safety in the mining industry and the unfnished legacy of mining accidents: Safety levers and defense-in-depth for addressing mining hazards," Safety Science, vol. 49, no. 6, pp. 764-777, 2011 